\title{
Intermittent Intraperitoneal Administration of Magnesium Sulphate in an Elderly Patient Undergoing Dialysis
}

\author{
Greg Egan, D Bruce Lange, Shelly Messenger, and Daniel Schwartz
}

\section{INTRODUCTION}

$\mathrm{H}$ ypomagnesemia is not a typical concern in patients with stage 5 chronic kidney disease. Magnesium $(\mathrm{Mg})$ is cleared renally, so $\mathrm{Mg}$ concentration is usually normal or even elevated in patients with chronic kidney disease. ${ }^{1-3}$ Up to $95 \%$ of renally filtered $\mathrm{Mg}$ can be reabsorbed in the nephron. ${ }^{1,2}$ Certain medications, such as diuretics (loop, thiazide, and osmotic), cisplatin, gentamicin, and B-lactam antibiotics, increase $\mathrm{Mg}$ excretion. ${ }^{2}$ The gastrointestinal absorption of $\mathrm{Mg}$ is dose-dependent and occurs by paracellular uptake at high $\mathrm{Mg}$ concentrations and by active transport at low $\mathrm{Mg}$ concentrations. ${ }^{2}$ Depending on the salt form, 30\%-50\% of ingested $\mathrm{Mg}$ is absorbed., ${ }^{1,2}$ Certain gastrointestinal disorders cause malabsorption, and certain medications, such as proton-pump inhibitors, reduce absorption, either of which can lead to hypomagnesemia. ${ }^{1,4-6}$ Renal dysfunction can lead to hypermagnesemia, yet gastrointestinal malabsorption can lead to hypomagnesemia; when these 2 conditions occur concurrently the change in serum magnesium is unpredictable. ${ }^{1,2}$

The clinical signs of hypomagnesemia range from fatigue, anemia, and hypokalemia to neuromuscular instability characterized by ataxia, vertigo, and hyperreflexia. ${ }^{1,2}$ Mild hypomagnesemia can be corrected by oral supplementation, with or without coadministration of vitamin $\mathrm{D}$ or a vitamin $\mathrm{D}$ analogue. In more severe cases, parenteral administration of magnesium sulphate is often required, most commonly by IV administration; however, in some cases, intraperitoneal (IP) administration of $\mathrm{Mg}$ has been successful in correcting hypomagnesemia. ${ }^{7-9}$ This report describes a patient with stage 5 chronic kidney disease whose hypomagnesemia was corrected by IP administration of magnesium sulphate.

\section{CASE REPORT}

An 81-year-old woman with stage 5 chronic kidney disease secondary to recurrent renal calculi and possible renal oxalosis (thought to be related to a jejunoileal bypass procedure in her fifth decade of life) presented with fatigue and weakness shortly after continuous ambulatory peritoneal dialysis (CAPD) was established.* The serum $\mathrm{Mg}$ concentration before initiation of CAPD was $0.7 \mathrm{mmol} / \mathrm{L}$, and the initial prescription for peritoneal dialysate was Nutrineal $\mathrm{Mg} 0.25 \mathrm{mmol} / \mathrm{L}$ (2 L) once daily and Dianeal $\mathrm{Mg} 0.25 \mathrm{mmol} / \mathrm{L}$ (2 L) once daily, with Extraneal Mg $0.25 \mathrm{mmol} / \mathrm{L} 3 \mathrm{~L}$ overnight (all products from Baxter). When the patient presented with the symptoms described above, her serum $\mathrm{Mg}$ was $0.4 \mathrm{mmol} / \mathrm{L}$ (normal range $0.7-1.2 \mathrm{mmol} / \mathrm{L})$. A medication review did not reveal an easily reversible cause of hypomagnesemia. Therefore, oral $\mathrm{Mg}$ supplementation was started, and Dianeal $\mathrm{Mg} 0.75 \mathrm{mmol} / \mathrm{L}$ was used in the peritoneal dialysate prescription. Both $\mathrm{Mg}$ hydroxide and $\mathrm{Mg}$ glucoheptonate were tried, with limited effect: the symptoms persisted and serum $\mathrm{Mg}$ concentration remained below $0.7 \mathrm{mmol} / \mathrm{L}$. Gastrointestinal malabsorption related to the patient's remote history of jejunoileal bypass surgery (about 35 years before) was specifically implicated as the cause of hypomagnesemia., ${ }^{5,6}$ Although hypomagnesemia is common, it typically responds to oral supplementation. To date, there have been no cases in the literature describing hypomagnesemia due to gastrointestinal malabsorption in patients with stage 5 chronic kidney disease.

Intermittent doses of $\mathrm{Mg}$ ( $2 \mathrm{~g}$ by IV infusion weekly) were started and eventually titrated to $\mathrm{Mg} 5 \mathrm{~g}$ IV weekly over a period of 2.5 months, but effectiveness was inconsistent (Figure 1). Because of persistent hypomagnesemia and the logistical challenges of maintaining IV access and scheduling weekly IV infusions of $\mathrm{Mg}$, IP administration of a higher concentration of $\mathrm{Mg}$ was considered. Previous case reports have described the potential for IP administration of $\mathrm{Mg}$ to cause abdominal pain (through chemical irritation of the peritoneum) and to increase

\footnotetext{
*The patient provided consent for publication of this case report.
} 


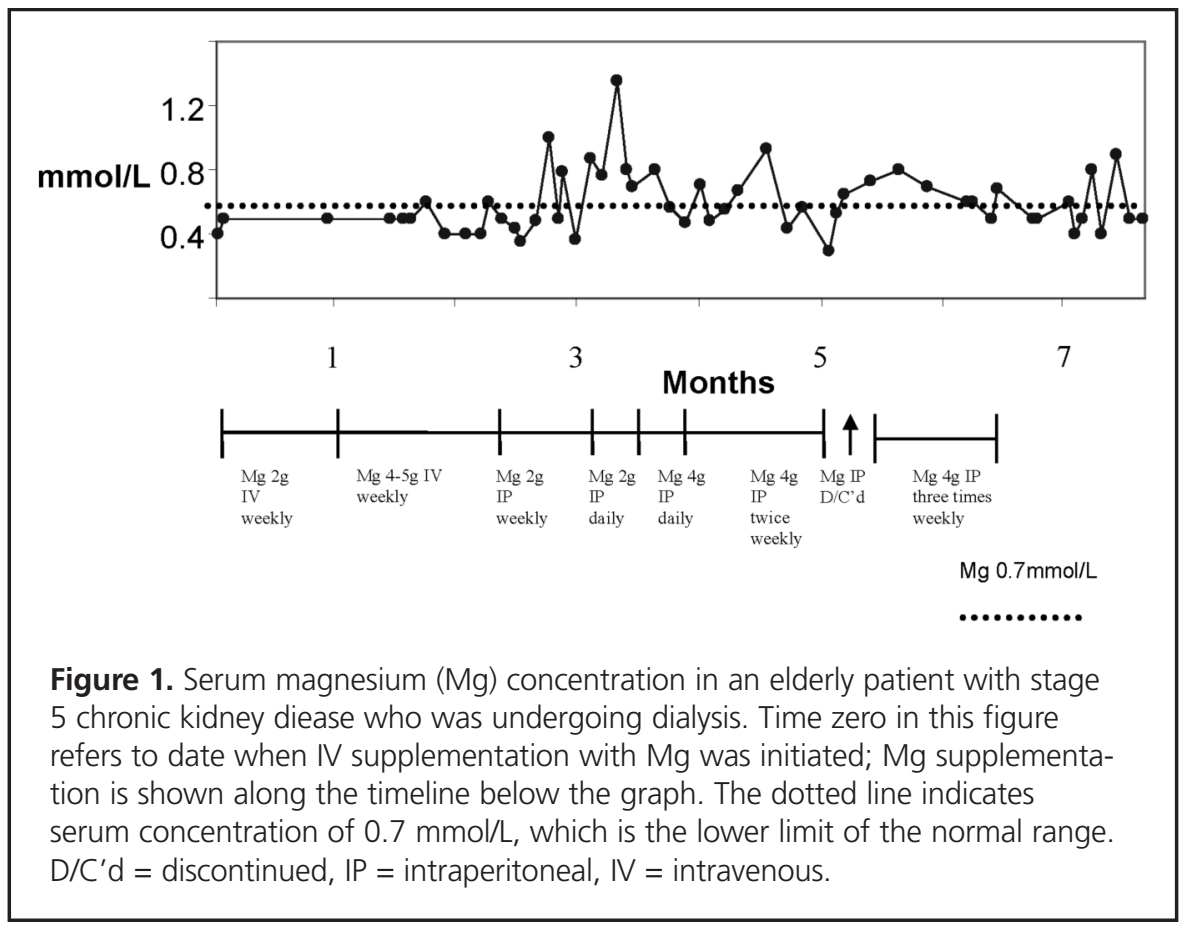

the risk of infection, although the rates of these complications have not been characterized. ${ }^{7.8}$

Starting at 2.5 months, additional $\mathrm{Mg}$ was administered IP once weekly, as $2 \mathrm{~g}(8 \mathrm{mmol})$ in the 2-L daytime dwell of Nutrineal. ${ }^{78}$ This dose was continued until 3 months (Figure 1). The patient did not experience any adverse effects, and the serum $\mathrm{Mg}$ concentration improved, but her symptoms persisted. From months 3 to 3.5, daily administration of $\mathrm{Mg} 2 \mathrm{~g}$ in the Nutrineal 2-L dwell was prescribed, although for 8 days within that period, $\mathrm{Mg} 4 \mathrm{~g}$ (16 mmol) was administered in the Nutrineal 2-L dwell. After this course, serum $\mathrm{Mg}$ concentration increased to $1.3 \mathrm{mmol} / \mathrm{L}$ and the dosage schedule was decreased to $\mathrm{Mg} 4 \mathrm{~g} \mathrm{IP}$ twice weekly during months 3.5 to 4.5 (Figure 1). Eventually, Mg 4 g IP 3 times weekly was prescribed to maintain serum $\mathrm{Mg}$ above $0.7 \mathrm{mmol} / \mathrm{L}$, and this dose was administered for months 5.5 to 6.5 (Figure 1). During month 5, IP administration of $\mathrm{Mg}$ was discontinued, and serum concentration dropped to $0.29 \mathrm{mmol} / \mathrm{L}$. IP administration of $\mathrm{Mg}$ was resumed at the previous prescription (4 g IP 3 times weekly), and serum $\mathrm{Mg}$ concentration increased to the normal range (Figure 1).

The patient was able to prepare and self-administer the $\mathrm{Mg}$ doses at home and tolerated this treatment with no apparent adverse effects (e.g., abdominal pain or signs of chemical peritonitis, such as cells in the dialysate effluent or hypermagnesemia). Unfortunately, because of incidental development of ischemic bowel, the peritoneal dialysis catheter had to be removed, and the mode of dialysis was converted to hemodialysis. At the time of writing (mid-2013), the patient continued to receive 2-g IV doses of Mg twice weekly during hemodialysis.

\section{DISCUSSION}

A literature search in Google Scholar, MEDLINE, Embase, and Scopus, with the search terms "magnesium", "hypomagnesemia", "intra-peritoneal administration", and "continuous ambulatory peritoneal dialysis", identified several case reports and one case series describing the relationship between IP administration of $\mathrm{Mg}$ and serum levels of this element. Bastani and Pandurangan ${ }^{7}$ described a woman who was not receiving dialysis and who had renal $\mathrm{Mg}$ wasting; her serum $\mathrm{Mg}$ concentration was maintained above $0.6 \mathrm{mmol} / \mathrm{L}$ for more than 3 years with magnesium sulphate $1 \mathrm{~g}(4 \mathrm{mmol})$ in $500 \mathrm{~mL}$ dextrose $5 \%$ in water (D5W) IP twice daily. The patient was initially treated with magnesium sulphate $2 \mathrm{~g}$ $(8 \mathrm{mmol})$ in $500 \mathrm{~mL}$ D5W; however, the higher concentration caused severe abdominal pain, which was thought to be related to chemical peritonitis. ${ }^{7}$ In the case series, 4 patients who were undergoing peritoneal dialysis and who had hypomagnesemia secondary to poor nutritional intake were successfully treated with IP Mg. ${ }^{8}$ These patients received magnesium sulphate $4 \mathrm{~g}$ (16 mmol) in $2 \mathrm{~L} 2.5 \%$ dextrose in the longest dwell during the day, every day. Serum Mg concentrations were sampled serially after the dose was instilled, with peak concentration observed between 4 and $6 \mathrm{~h}$. Serum $\mathrm{Mg}$ concentration within the normal range persisted over a 24-h period. In 3 of the cases, IP administration of $\mathrm{Mg}$ was continued once weekly for over a 
year. Normal serum $\mathrm{Mg}$ concentration was maintained, with no adverse effects or significant hypermagnesemia. ${ }^{8}$ Three separate reports also described the relationship between administration of $\mathrm{Mg}$ in standard peritoneal dialysis solutions and serum $\mathrm{Mg}$ concentration. ${ }^{7,10,11}$ In patients receiving standard dialysate solutions containing $\mathrm{Mg} 0.25 \mathrm{mmol} / \mathrm{L}, 0.5 \mathrm{mmol} / \mathrm{L}$, or $0.75 \mathrm{mmol} / \mathrm{L}$, serum $\mathrm{Mg}$ concentrations ranged from 0.6 $\mathrm{mmol} / \mathrm{L}$ to $1 \mathrm{mmol} / \mathrm{L} .{ }^{8.911}$ In one of these studies, 5 patients receiving $\mathrm{Mg} 0.25 \mathrm{mmol} / \mathrm{L}$ peritoneal dialysate solutions experienced hypomagnesemia that persisted despite oral $\mathrm{Mg}$ supplementation. The $\mathrm{Mg}$ concentration was increased to $0.75 \mathrm{mmol} / \mathrm{L}$, and serum $\mathrm{Mg}$ concentration normalized ${ }^{9}$ ( $0.75 \mathrm{mmol}$ is equivalent to $0.188 \mathrm{~g} \mathrm{Mg}$, such that four 2-L exchanges would provide a total of $1.5 \mathrm{~g} \mathrm{Mg}$ per $24 \mathrm{~h}$ ). These cases reinforce the relationship between IP administration of $\mathrm{Mg}$ and serum $\mathrm{Mg}$ concentration, providing further evidence that administration of $\mathrm{Mg}$ by the IP route is a feasible strategy to correct hypomagnesemia in certain circumstances.

One approach to managing symptomatic hypomagnesemia in a patient who is undergoing CAPD would be to first identify any medication or dietary causes of $\mathrm{Mg}$ deficiency that are easily reversible. The second step would be to increase the amount of $\mathrm{Mg}$ to the maximum commercially available strength. If the hypomagnesemia persists, consider adding $\mathrm{Mg}$ $2 \mathrm{~g}(8 \mathrm{mmol})$ to the longest dwell of the day, and titrate up to $\mathrm{Mg} 4 \mathrm{~g}(16 \mathrm{mmol})$ in the longest dwell of the day. The high dose of $\mathrm{Mg}$ by IP administration may be given daily initially and then tapered to the lowest effective dose over a period of a month or two, according to weekly serum $\mathrm{Mg}$ concentrations. The patient should be monitored for development of chemical peritonitis, which has been reported to occur at $\mathrm{Mg}$ concentrations greater than $16 \mathrm{mmol} / \mathrm{L}$ in dialysate solution, and for occurrence of bacterial peritonitis.

Here, we have reported the successful use of intermittent IP administration of $\mathrm{Mg}$ sulphate in a patient with stage 5 chronic kidney disease who was experiencing symptomatic hypomagnesemia. IP administration of $\mathrm{Mg}$ corrected the hypomagnesemia and did not result in hypermagnesemia or other adverse effects such as chemical peritonitis or bacterial peritonitis.

\section{References}

1. Baker SB, Worthley LIG. The essentials of calcium, magnesium and phosphate metabolism: Part II. Disorders. Crit Care Resusc. 2002;4(4):307-15.

2. Whang R, Hampton EM, Whang DD. Magnesium homeostasis and clinical disorders of magnesium deficiency. Ann Pharmacother. 1994; 28(2):220-6.
3. Navarro JF, Mora C, Macia M, Garcia J. Serum magnesium concentration is an independent predictor of parathyroid hormone levels in peritoneal dialysis patients. Perit Dial Int.1999;19(5):455-61.

4. Johansson HE, Zethelius B, Ohrvall M, Sundbom M, Haenni A. Serum magnesium status after gastric bypass surgery in obesity. Obes Surg. 2009;19(9):1250-5.

5. Hocking MP, Davis GL, Franzini DA, Woodward ER. Long-term consequences after jejunoileal bypass for morbid obesity. Dig Dis Sci. 1998;43(11):2493-9.

6. Greenberg A. Primer on kidney diseases. 4th ed. National Kidney Foundation; 2005. p. 131-5.

7. Bastani B, Pandurangan G. Intraperitoneal route of magnesium sulphate supplementation in a patient with severe renal magnesium wasting. Nephrol Dialysis Transplant. 2001;16(10):2086-9.

8. Amirmokri P, Morgan P, Bastani B. Intra-peritoneal administration of potassium and magnesium: a practical method to supplement these electrolytes in peritoneal dialysis patients. Renal Failure. 2007;29(5):603-5.

9. Eisenman K, Holley JL. A higher magnesium dialysate concentration treats hypomagnesemia. Perit Dial Int. 2005;25(6):604-5.

10. Saha HHT, Harmoinen APT, Pasternack AI. Measurement of serum ionized magnesium in CAPD patients. Perit Dial Int.1997;17(4):347-52.

11. Ejaz AA, McShane AP, Gandhi VC, Leehey DJ, Ing TS. Hypomagnesemia in continuous ambulatory peritoneal dialysis patients dialyzed with a lowmagnesium peritoneal dialysis solution. Perit Dial Int. 1995;15(1):61-4.

Greg Egan, BScPharm, ACPR, was, at the time of writing, a pharmacy resident in the Lower Mainland Pharmacy Department and the Faculty of Pharmaceutical Sciences at the University of British Columbia, Vancouver, British Columbia.

D Bruce Lange, BScPharm, ACPR, PharmD, is a Clinical Pharmacist Specialist in nephrology in the Fraser Health Renal Program, New Westminster, British Columbia. He is also a clinical instructor in the Faculty of Pharmaceutical Sciences, University of British Columbia, Vancouver, British Columbia.

Shelly Messenger, BSc, RD, is a Renal Dietician in the Fraser Health Renal Program, New Westminster, British Columbia.

Daniel Schwartz, MD, FRCPC, is a Nephrologist and Medical Director of the Fraser Health Renal Program, New Westminster, British Columbia, and a Clinical Assistant Professor in the Faculty of Medicine at the University of British Columbia, Vancouver, British Columbia.

Competing interests: None declared.

Address correspondence to:

Greg Egan

Pharmacy

Royal Columbian Hospital

330 East Columbia Street

New Westminster BC V3K 3W7

e-mail: gregory.egan@fraserhealth.ca 